\title{
The trauma of peer abuse: effects of relational peer victimization and social anxiety disorder on physiological and affective reactions to social exclusion
}

\author{
Benjamin Iffland $^{1}{ }^{*}$, Lisa Margareta Sansen $^{1,2}$, Claudia Catani $^{1}$ and Frank Neuner ${ }^{1}$ \\ 1 Department of Psychology, Bielefeld University, Bielefeld, Germany \\ ${ }^{2}$ Christoph-Dornier-Stiftung für Klinische Psychologie, Bielefeld, Germany
}

\section{Edited by:}

John Vijay Sagar Kommu, National

Institute of Mental Health and

Neurosciences, India

Reviewed by:

Jacek Debiec, University of Michigan, USA

John Vijay Sagar Kommu, National Institute of Mental Health and

Neurosciences, India

Preeti Kandasamy, National Institute of Mental Health and Neurosciences, India

\section{*Correspondence:}

Postbox 100131, Bielefeld 33501 ,

Germany

e-mail: benjamin.iffland@

uni-bielefeld.de
Benjamin Iffland, Department of

Psychology, Bielefeld University,

Background: Social exclusion elicits emotional distress, negative mood, and physiological stress. Recent studies showed that these effects were more intense and persisting in socially anxious subjects. The present study examined whether the abnormal reactions of socially anxious subjects can be traced back to previous experiences of relational peer victimization during childhood and adolescence.

Methods: Participants $(N=74)$ were patients with a diagnosis of social anxiety disorder as well as healthy controls. The patient and control groups were subdivided into two subgroups according to the subject's reports about previous relational peer victimization. Immediate and delayed physiological (skin conductance level and heart rate) and affective reactions to a simulated social exclusion in a ball-toss game (Cyberball) were recorded.

Results: Overall, subjects' immediate reactions to social exclusion were an increase in skin conductance and a reduction of positive affect. Regardless of the diagnostic status, subjects with a history of relational peer victimization showed a more intense self-reported affective change that was accompanied by a blunted skin conductance response. However, the mood of the subjects with a history of peer victimization recovered during a $15 \mathrm{~min}$ waiting period. A diagnosis of social anxiety disorder did not affect the reactions to social exclusion on any measure.

Conclusion: Findings indicate that stress reactions to social exclusion depend more on previous experiences of peer victimization than on a diagnosis of social anxiety disorder. The findings indicate that memories of negative social experiences can determine the initial stress reaction to social threats.

Keywords: cyberball, social anxiety disorder, peer victimization, social exclusion, autonomic arousal, physiological indices

\section{INTRODUCTION}

Aversive experiences during childhood and adolescence can have lasting consequences and contribute to different psychological disorders including depression and anxiety disorders (1-5). Second to traumatic events that involve a threat to life and limb, it is aversive social experiences that can be detrimental for mental health. Traumatic social experiences include emotional abuse and neglect by caretakers $(6,7)$ as well as non-physical forms of abuse by peers (also referred to as relational peer victimization). Relational peer victimization involves abusive acts like bullying, verbal threats or aggression, malicious manipulation of a relationship, friendship withdrawal, and damaging another's peer relationships (8). Peer victimization increases the risk of various forms of psychopathology (9) but is particularly linked to sub-clinical social anxiety $(8,10-12)$ as well as social anxiety disorder (SAD; 13). SAD is a common anxiety disorder that is characterized by fear of social situations and negative evaluation, and caused by an interplay of a genetic vulnerability and negative social learning experiences (14-16).
However, the mechanisms that link experiences of victimization and later psychopathology are still unclear. Recently, models of cognitive vulnerability $(17,18)$ that are related to memory models of traumatic events (19) as well as network models of emotions (20) have suggested that negative learning experiences may form associative memory representations that may trigger stereotype and pathological reactions in similar social situations. In this understanding, the cognitive vulnerability for social anxiety $(17,18,21)$ caused by peer victimization may be modeled as a strong associative memory representation that consists of a network of characteristic stimulus and response elements of the traumatic social situation. Later on, specific environmental features that remind the individual of experiences of relational peer victimization may automatically trigger the recurrence of symptoms of anxiety and fear, even if the current situation is not threatening $(18,22)$. As a consequence, several social situations are likely to elicit a spectrum of behavioral, autonomic, and endocrine responses that normally only occur in the context of danger (23). In accordance with this idea, Hackmann et al. (24) reported that 
the majority of patients with social anxiety disorder could identify a particular memory, which they felt was closely linked to the recurrence of symptoms of social anxiety disorder.

This conceptualization predicts that everyday social challenges may provoke more intense reactions in subjects with a history of victimization as such events could trigger associative response elements of the social traumatic experience. With this study we aimed to test this hypothesis. According to Lang (20), the response elements of such associative networks include physiological elements. As a consequence, the responses to social situations that remind the individual of similar earlier experiences should be accompanied by more intense physiological responses in subjects with a history of victimization. While prior studies have shown that subjects with PTSD presented with increased heart rate, skin conductance level (SCL), and blood pressure after presentation of trauma relevant stimuli (25-30), there is currently minimal evidence that these findings can be transferred to non-physical forms of violation, and disorders other than PTSD.

A key element of relational peer victimization is social exclusion $(31,32)$, which can be experimentally simulated (33-36). For the purpose of this study, we referred to the Cyberball paradigm as an experimental intervention that might serve as a reminder of previous relational victimization. Cyberball is a virtual ball-tossing game $(35,37)$ where participants are told that they would be playing with two or more co-players on the computer and to mentally visualize the situation, themselves and the other players. In general, the exclusion evokes negative mood and brings about reduced feelings of belonging, self-esteem, control, and meaningful existence, with socially excluded subjects showing a more intense reaction (e.g., 33, 35, 36).

In socially anxious subjects, the Cyberball game elicited immediate and delayed effects on psychological outcomes $(38,39)$. Highly anxious subjects reported more psychological distress than low anxious participants immediately after the Cyberball game. Moreover, $45 \mathrm{~min}$ after the Cyberball game, highly socially anxious subjects still reported more distress than low anxious subjects who had returned to their baseline levels. Additionally, exclusion during Cyberball has been demonstrated to elicit self-regulatory deficits that persisted only in highly anxious subjects forty-five minutes after the exclusion episode (40).

In addition, neuro-imaging studies revealed that processing of social exclusion activates a neural network that is associated to the processing of physical pain (41-43). However, so far there is little research on the peripher-physiological responses to social exclusion. Kelly et al. (44) showed that independent of condition, arousal as measured by SCL decreased over the course of time. However, arousal of the excluded subjects did not decrease to the same extent as the included subjects' arousal. Consistent with this finding, social exclusion implemented by Cyberball was associated with significant changes in SCL in a sample of 119 female children and adolescents from a private residential summer camp (45). During the Cyberball game, subjects showed heightened SCLs. However, there were no effects of social exclusion on heart rate. The Cyberball game did not elicit physiological reactions as measured by heart rate and cortisol level in a sample of 18 healthy students (46).
The aim of this study was to explore the impact of experiences of peer victimization and social anxiety on physiological and psychological reactions to social exclusion. We postulated that immediately after the Cyberball game subjects reporting a history of relational peer victimization would show higher levels of physiological activation as measured by SCL and heart rate than subjects without peer victimization experiences. Furthermore, subjects high on peer victimization should report less positive affect and more negative affect in reaction to social exclusion. We postulated that these reactions would be stable over a waiting period of $15 \mathrm{~min}$. Furthermore, assuming memory representations are potential mediators between victimizations and pathology, we hypothesized that the effect of a history of victimization would be even stronger for subjects with SAD.

\section{MATERIALS AND METHODS PARTICIPANTS}

Participants were recruited through the Outpatient Psychotherapy Clinic of Bielefeld University and bulletins at the campus of Bielefeld University. Participants included 37 (29 females) individuals who met DSM-IV-TR (47) criteria for a diagnosis of social anxiety disorder and 37 healthy controls (30 females). Exclusion criteria included (a) any current DSM-IV Axis I psychiatric disorder other than social anxiety disorder without a co-morbid SAD, (b) evidence of a current substance abuse or dependence, (c) evidence of current or past psychosis, (d) evidence of acute suicide intention or ideation, and (e) current medication altering physiological reactivity. Moreover, assuming that they might be too suspicious of the experimental manipulation, subjects currently enrolled at the faculty of psychology at Bielefeld University were rejected from participation. The demographic characteristics of the sample are presented in Table 1.

\section{INSTRUMENTS}

\section{Diagnosis of social anxiety disorder}

Diagnostic status was assessed using the German Version of the Mini International Neuropsychiatric Interview (MINI; 48-50). The MINI is a structured clinical interview designed to generate diagnoses for the main diagnostic and statistical manual (DSM)-III-R/IV Axis I disorders. The interviews were conducted by Master-level clinical psychologists who were trained in the application of the MINI.

\section{Social anxiety symptoms}

For the assessment of the severity of symptoms of social anxiety disorder, the German version of the social phobia scale/social interaction anxiety scale (SPS/SIAS; 51) was used. The SPS was developed to assess anxiety related specifically to social performance, whereas the SIAS was designed to measure anxiety related to general social interaction. Both, the SPS and the SIAS consist of 20 items using a five-point Likert scale that are rated from 0 (not at all) to 4 (extremely) indicating how characteristic or true the statements are for the respondent. On both scales total-scores range from 0 to 80 . Cut-off scores of 20 on the SPS and 30 on the SIAS indicate a clinically relevant level of social anxiety (52). The German version of the SPS/SIAS has shown high levels of internal consistency and convergent, but deficient discriminant validity (51). 
Table 1 | Subject characteristics and mean values on the assessments $(N=74)$.

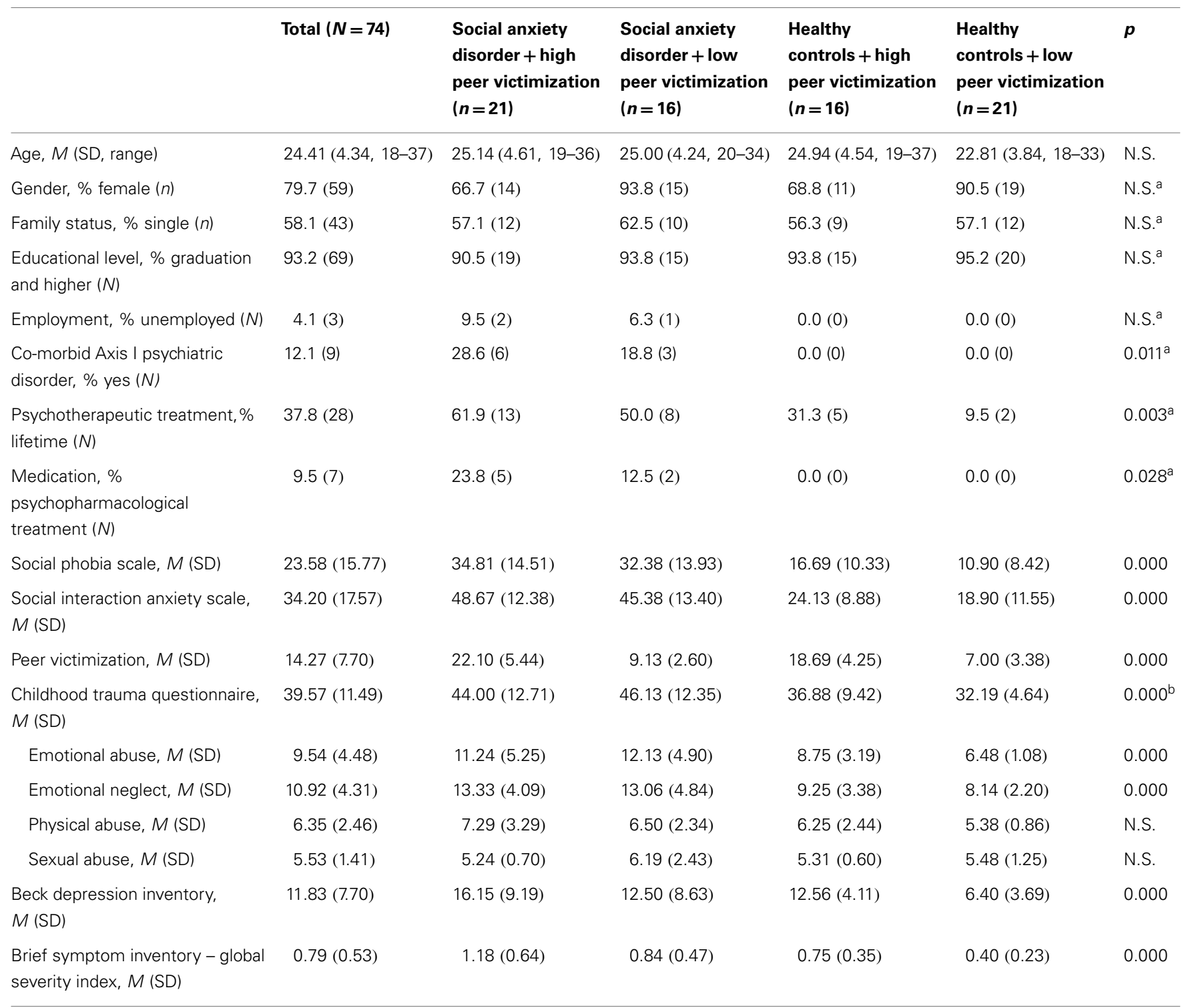

${ }^{a}$ Chi-Quadrat-Test.

${ }^{b}$ CTQ sum score for the 28-item version.

\section{Relational peer victimization}

To assess relational peer victimization, we used a checklist that was recently developed and validated in our working group (53). The Fragebogen belastender Sozialerfahrungen (FBS; questionnaire on stressful social experiences) assesses various forms of abusive experiences occurring amongst peers. It consists of a list of 22 aversive social situations (i.e., "I was excluded from games or activities by other children or adolescents," "I have been laughed at in the presence of other children"). For each situation respondents are asked whether or not (Yes or No) they have experienced this situation during childhood (age of 6-12) or adolescence (age of 13-18). The total-score is calculated as a sum of "Yes" responses in of both age periods and ranges from 0 to 44 . The total-score showed a satisfying stability over a period of 20 months $(r=0.89)$. Construct validity has been confirmed through correlations with measures of psychological symptom distress and social anxiety. Moderate correlations with the scales of the CTQ and an incremental contribution to the prediction of psychopathology indicate that the FBS assesses an additional construct of child maltreatment.

\section{Child maltreatment}

The German version of the childhood trauma questionnaire (CTQ; 54) was used to assess different types of childhood maltreatment. The 28 -item self-rated scale distinguishes five areas of maltreatment (sexual abuse, emotional neglect, emotional abuse, physical neglect, and physical abuse). The items are rated from 1 (never true) to 5 (very often true) with a possible range of subscale scores of 5-25. The psychometric properties of the German 
version were similar to the original version and it has been shown to be a reliable and valid screen for childhood maltreatment. Internal consistency of all scales except physical neglect was shown to be high (Cronbach's $\alpha>0.89$ ). Correlations with self-reported measures for post-traumatic stress, dissociation, and general psychopathology were low to moderate (54). However, in a recent validation study from the general population (55), the five factor structure of the original version showed only a moderate fit. As the physical neglect subscale was highly correlated with the other subscales, presented with a weak internal consistency in comparison to the other subscales, and since the fit of a four factor structure excluding the physical neglect items was much superior to the five factor model, the physical neglect subscale and its items were disregarded in the following analyses (55). In the present study, Cronbach's alpha was $\alpha=0.73$ for all items. Internal consistency of all scales was acceptable to high (Cronbach's $\alpha>0.75$ ).

\section{Symptoms of depression}

Symptoms of depression were measured using the German version of the Beck depression inventory (BDI-II; 56). The selfreport measure consists of 21 items relating to symptoms of depression. The items are rated on a four-point scale indicating the severity of symptoms and are considered to be rated for the experience of the past 2 weeks including today. Higher scores indicate more severe depressive symptoms. The BDI-II has shown good psychometric properties in clinical and non-clinical samples (57).

\section{General psychopathology}

In order to measure psychopathology and psychological distress, the German version of the brief symptom inventory (BSI; 58-60) was used. The BSI is a 53-item short form of the symptom check List 90 (SCL-90). It produces the same nine primary symptom dimensions (somatization, obsessive-compulsivity, interpersonal sensitivity, depression, anxiety, hostility, phobic anxiety, paranoid ideation, and psychoticism). Furthermore, three global indices measure general psychological distress. These include the global severity index (GSI), the positive symptom total (PST), and the positive symptom distress index (PSDI). Each item is rated on a five-point Likert scale ranging from 0 (not at all) to 4 (extremely) and is considered to be rated for the experience of the past 7 days including today.

\section{Positive and negative affect}

For the assessment of positive and negative affect in reaction to social exclusion, the German version of the positive and negative affect schedule was used (PANAS; 61, 62). The PANAS was developed to assess positive and negative affect measured on a five-point Likert scale ranging from 1 (very slightly) to 5 (extremely). It is intended to gain information on a participant's emotional state at the moment that the questionnaire is given. The positive and negative affect scales consist of 10 items each. The scales were shown to be largely uncorrelated (62). The German version showed good internal consistency (Cronbach's $\alpha>0.84 ; 61$ ).

\section{Manipulation checks}

There were two manipulation checks to confirm participants' perception of their inclusionary status. First, they were asked to estimate the percent of throws they had received ("Assuming that $33 \%$ of the time you would receive the ball if everyone received it equally, what percent of the throws did you receive?"). Second, they were asked to rate how much they felt excluded while playing the Cyberball game on a nine-point Likert scale ranging from 1 (very included) to 9 (very excluded). In addition, participants had the chance to write down their thoughts during the Cyberball game (35) and to comment on their thoughts.

\section{Procedure}

The study was conducted within two sessions. The second session was scheduled on average 10 days after the first session. At the first session, participants provided written informed consent at the beginning of the assessment. The consent form stated that the purpose of the study was to "evaluate the relationship of mental visualization and psychological distress.” Subjects were informed that participation was voluntary, and that they could discontinue at any time. Following, participants were administered the MINI (49) to determine diagnostic status. Afterward, they were invited to fill in a socio-demographic questionnaire as well as the study questionnaires (see below). At the second session, skin conductance and electrocardiogram (ECG) leads were positioned on participants with the assistance of the research assistants. To assess skin conductance, $9 \mathrm{~mm}$ electrodes were attached to the thenar and hypothenar surface of the non-dominant hand. A layer of an isotonic electrolyte gel was placed on the electrodes to increase conduction. For the assessment of heart rate signals, participants placed three disposable $\mathrm{Ag} / \mathrm{AgCl}$ electrodes on the manubrium sterni, the lowest part of the sternum and the lowest left rib. Skin conductance and heart rate were registered and digitized using a Varioport biosignal recording device (Becker Meditec, Karlsruhe, Germany), that was controlled by a Windows computer with Variograph software (Becker Meditec, Karlsuhe, Germany). Skin conductance and heart rate were recorded simultaneously with a sampling rate of $512 \mathrm{~Hz}$. Skin conductance signal was converted to microsiemens $(\mu \mathrm{S})$ and heart rate signal to beats per minute (bpm). Skin conductance was missing for three participants and heart rate for four due to experimenter error.

Baseline physiological activity (skin conductance and heart rate) was assessed during a 3-min period of rest. During this period, participants were instructed to sit quietly and relax. Afterwards, participants were asked to fill in baseline assessments of affect. Next, participants were informed that to practice and test mental visualization, they would be playing a virtual ball-tossing game called "Cyberball" with what they believed to be two other players (35). In reality, these players were computer generated. Participants were instructed to mentally visualize (as vividly as possible) the scene throughout the game ("Imagine what the others look like. What sort of people are they? Where are you playing? Is it warm and sunny or cold and rainy?"). Shortly after the instruction, the experimenter received a staged phone call informing them that the other players were ready to start. Then the game began.

At the beginning of the game, the participants received the ball and were then required to indicate to whom they would like to throw the ball by clicking on the appropriate player icon. After receiving the ball twice, participants were excluded from the game and did not receive the ball ever again. The game lasted for a total 
of 30 throws. Following the game, participants filled in the affect scales and the manipulation checks (see above).

After completing the questionnaires, participants were told that the experimenter would have to check recordings of the physiological signals of the other players and were instructed to stay on their chair and wait until the experimenter returned to remove the electrodes. At the end of a waiting period of $15 \mathrm{~min}$, the experimenter returned and asked the participants to fill in the affect scales. Skin conductance and heart rate were recorded continuously throughout the ball-tossing game and the waiting period.

Finally, participants were debriefed and had the chance to comment on the study and ask questions of the researchers. The study was approved by the Ethical Committee of the Department of Psychology of Bielefeld University.

\section{Data reduction and analyses}

Physiological data were pre-processed and analyzed using MATLAB version 7.7 (2008b, The MathWorks, Natick, MA, USA) with the toolboxes ANSLAB (63) and Ledalab (available under www.ledalab.de). R-waves in the ECG data were identified automatically by ANSLAB software (63) and converted to bpm. Additionally, a visually artifact inspection was conducted. Artifactual data points were manually replaced, non-recognized R-waves were edited and sections with high proportions of artifacts were not evaluated. Similarly, raw data of skin conductance were screened for implausible artifacts and manually edited. For further analyses, mean levels of skin conductance and heart rate, respectively, during baseline ( $3 \mathrm{~min}$ ), the Cyberball game ( 3 to $5 \mathrm{~min}$ ) and the waiting period $(15 \mathrm{~min})$ were used.

\section{Statistical analyses}

All statistical analyses were carried out using the Statistical Package for the Social Sciences SPSS 20. To test the reactions to social exclusion dependent on the extent of social anxiety and peer victimization, 2 (social anxiety disorder vs. control group) $\times 2$ (high vs. low peer victimization) $\times 2$ (time: baseline, Cyberball and Cyberball, waiting period) analyses of variance (ANOVAs) with repeated measurement on the third factor were conducted. In a first step, effects of social exclusion were analyzed regarding assessments at baseline and during/after the Cyberball game. In a second step, assessments during/after the Cyberball game and during/after the waiting period were used to analyze effects of the waiting period. Additionally, all ANOVAs were carried out as analyses of covariance (ANCOVAs) with the CTQ sum score serving as covariate to control for the influence of childhood maltreatment. Similarly, to control for the influence of co-morbid psychiatric disorders on the reactions to social exclusion ANCOVAs with the diagnostical status of a current major depressive disorder (MDD) serving as covariate were carried out. As the pattern of results did not change, ANOVAs are reported.

\section{RESULTS}

The total sample consisted of 74 subjects, predominantly women $(n=59,79.7 \%)$, of which 37 individuals $(50.0 \%)$ were diagnosed with social anxiety disorder. In nine individuals diagnosed with social anxiety disorder a co-morbid current MDD was determined. The average age was $M=24.41(\mathrm{SD}=4.34)$. Table 1 presents participants' means on the assessments.

\section{SKIN CONDUCTANCE LEVEL}

For SCL reactivity to social exclusion, the ANOVA showed a significant interaction of time and peer victimization, $F(1,68)=4.83$; $p=0.031 ; \eta^{2}=0.066$. The interaction of time and social anxiety did not reach significance, $F(1,68)=1.12 ; p=0.293 ; \eta^{2}=0.016$. In addition, the ANOVA showed a significant main effect of time, $F(1,68)=26.42 ; p<0.001 ; \eta^{2}=0.280$. For the waiting period, neither the interaction of time and peer victimization, $F(1$, $68)=1.01 ; p=0.318 ; \eta^{2}=0.015$, nor the interaction of time and social anxiety, $F(1,68)=0.77 ; p=0.384 ; \eta^{2}=0.011$, were significant. Furthermore, there was no significant main effect of time, $F(1,68)=0.06 ; p=0.809 ; \eta^{2}=0.001$ (see Figure 1A).

\section{HEART RATE REACTIVITY}

For heart rate reactivity to social exclusion, the ANOVA showed no significant effects [time: $F(1,66)=0.40 ; p=0.531 ; \eta^{2}=0.006$; time $\times$ peer victimization: $F(1,66)=0.94 ; p=0.336 ; \eta^{2}=0.014$; time $\times$ social anxiety: $\left.F(1,66)<0.01 ; p=0.977 ; \eta^{2}<0.001\right]$. Similarly, no significant effects were found for the waiting period [time: $F(1,65)=1.21 ; p=0.275 ; \eta^{2}=0.018$; time $\times$ peer victimization: $F(1,65)=0.56 ; p=0.459 ; \eta^{2}=0.008$; time $\times$ social anxiety: $F(1$, $\left.65)=0.12 ; p=0.728 ; \eta^{2}=0.002\right]$ (see Figure 1B).

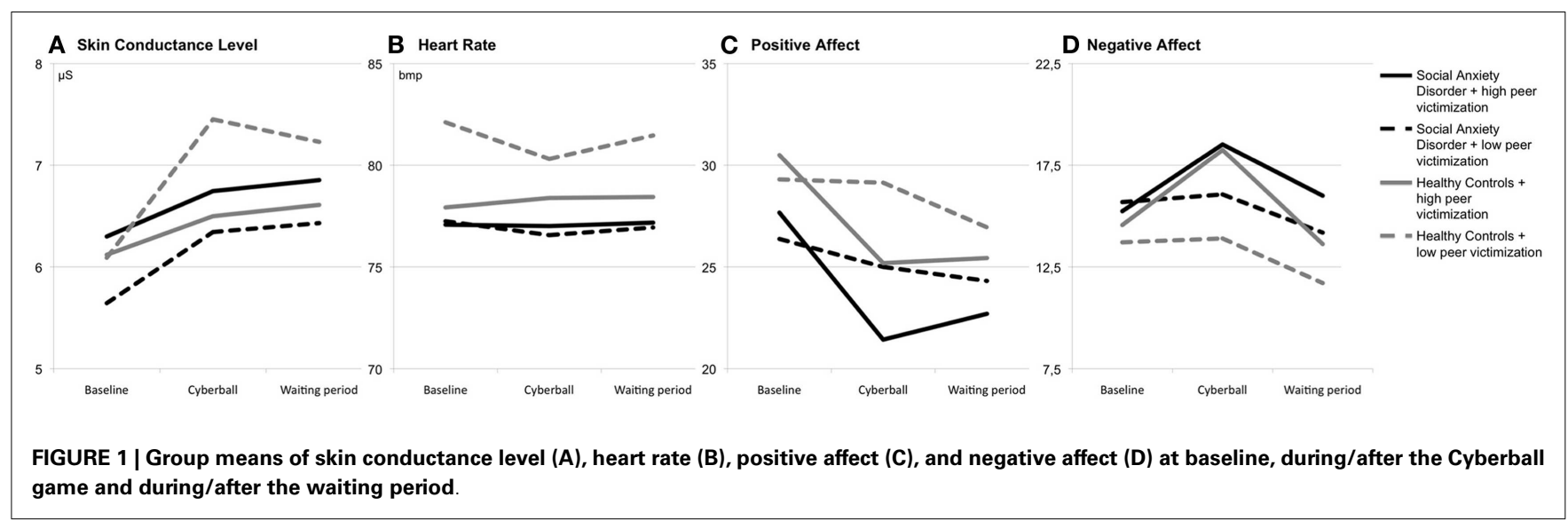




\section{POSITIVE AFFECT}

On the ratings of the positive affect, the ANOVA showed a significant interaction of time $\times$ peer victimization, $F(1,70)=11.75$; $p=0.001 ; \eta^{2}=0.144$. There was no significant interaction of time $\times$ social anxiety, $F(1,70)=0.53 ; p=0.471 ; \eta^{2}=0.007$. In addition, the ANOVA revealed a significant main effect of time, $F(1,70)=20.28 ; p<0.001 ; \eta^{2}=0.225$. No significant interaction of time $\times$ peer victimization, $F(1,70)=3.76 ; p=0.057$; $\eta^{2}=0.051$, was found in the ANOVA for the waiting period. Furthermore, the ANOVA showed no significant interaction of time $\times$ social anxiety, $F(1,70)=1.24 ; p=0.269 ; \eta^{2}=0.017$, and no significant main effect of time, $F(1,70)=0.35 ; p=0.557$; $\eta^{2}=0.005$ (see Figure 1C).

\section{NEGATIVE AFFECT}

The ANOVA showed a significant interaction of time $\times$ peer victimization, $F(1,70)=6.07 ; p=0.016 ; \eta^{2}=0.080$, for the ratings of negative affect. No significant effect was found for the interaction of time $x$ social anxiety, $F(1,70)=0.01 ; p=0.934 ; \eta^{2}<0.001$. However, the ANOVA showed a significant main effect of time, $F(1,70)=8.41 ; p=0.005 ; \eta^{2}=0.107$. For the waiting period, neither the interaction of time $\times$ peer victimization, $F(1,70)=1.71$; $p=0.195 ; \eta^{2}=0.024$, nor the interaction of time $x$ social anxiety, $F(1,70)=1.05 ; p=0.309 ; \eta^{2}=0.015$, were found to be significant. However, the ANOVA showed a significant main effect of time, $F(1,70)=22.63 ; p<0.001 ; \eta^{2}=0.244$ (see Figure 1D).

\section{DISCUSSION}

In a sample of subjects diagnosed with social anxiety disorder and healthy controls, we found that reactions to an episode of social exclusion were primarily influenced by the degree of relational peer victimization rather than by the diagnosis of SAD. While an increase in skin conductance immediately after the exclusion was observed for all groups of subjects, this physiological response was attenuated among the subjects with a history of peer victimization, while the affective responses were more intense. However, after a waiting period of $15 \mathrm{~min}$ the positive affect of the group of subjects with victimization increased again.

In general, social exclusion causes a physiological stress response. Across all subjects, we observed an increase in skin conductance immediately after the exclusion simulation. As our study lacks a control group of non-excluded subjects, we cannot exclude that the increase of skin conductance at this time point can be attributed to confounding factors. However, higher SCLs were reported in the exclusion than in the inclusion condition (44). Kelly et al. (44) proposed that these higher arousal levels are linked to stress associated with social pain, arguing that brain regions associated with increases in SCLs [i.e., anterior cingulated cortex (64)] are also activated when subjects were experiencing social exclusion (42). Moreover, the same regions are activated when individuals were confronted with the distress of physical pain (65) and loss of social connections (see 66 for review). However, the physiological response to social exclusion was restricted to skin conduction, we could not observe any effect on heart rate. In accordance with this, Krimsky (46) reported no differences in heart rate variability and cortisol level between included and excluded subjects after the Cyberball game.
Krimsky (46) suggested that the Cyberball paradigm was not effectively powerful in eliciting substantial and consistent physiological responses.

The immediate affective and physiological reaction to social exclusion is predicted by previous experiences of relational peer victimization. While we confirmed the hypothesis that subjects with a history of victimization present with a more intense affective reaction, their physiological response was, contrary to our expectations, attenuated rather than increased. This finding indicates that repetitive experiences of peer victimization may produce a qualitative rather than quantitative change of the autonomic nervous system response to social challenges. This idea is consistent with a large number of previous studies finding that the experience of adverse life events alters the regulation of the neurohormonal stress response (67-69). Healthy subjects with a history of childhood maltreatment showed blunted cortisol responses to psychological stress and diminished reactions to direct endocrine challenges (70-77). Similar patterns of cortisol responses to stressors were found for relational peer victimization $(78,79)$. In addition, Lovallo et al. (80) studied the impact of maltreatment on the autonomic nervous system and found that subjects who experienced adverse life events in childhood and adolescence showed not only an attenuated cortisol but also a blunted heart rate response. Recent findings indicated blunted rather than increased physiological responses in patients with multiple-trauma PTSD (81-83). Taken together, there is reason to conclude that repeated adversities including peer victimization cause a dissociation of the affective and physiological response to social stressors, with an intense selfreported affective change accompanied by a blunted physiological reaction. So far, it is unclear whether this reduction of physiological response is caused by a single mechanism that controls the different stress axes $(84,85)$, or whether a simultaneous change of the functioning of the single axes themselves, as currently discussed for the hormonal HPA axis (67-69) is responsible for this effect. However, the qualitative difference of the responses shows that it is too simplistic to assume a single conditioning or associative mechanism to explain the effects of repeated aversive experiences like peer victimization.

Contrary to our expectations and to previous findings (38-40) we could not find any influence of social anxiety on the responses to social exclusion. This finding contrasts with previous evidence of increased reactions (i.e., enhanced skin conductance, heart rate, and potentiated startle) to social threat in subjects with social anxiety (86-88). However, as peer victimization is highly linked to social anxiety disorder (13) it may be speculated that the association of social anxiety and pathological responses to social exclusion presented in previous studies may be produced by experiences of peer victimization or emotional maltreatment rather than psychopathology per se. In addition, relational peer victimization caused increased sensitivity to social exclusion even when analyses incorporated experiences of child maltreatment, suggesting that experiences of peer victimization have an independent and specific impact on reactions to social exclusion.

The present study has several limitations. Assessment of peer victimization and child maltreatment was based on retrospective accounts and self-report, both of which are subject to recall biases (89). Subjects with social anxiety may be more likely to be biased in 
estimating the occurrence of negative social situations. However, analyses of the validity of retrospective reports showed that distortions are present but not sufficiently large enough to invalidate retrospective studies (90). Moreover, in retrospective assessments of childhood maltreatment, under-reporting was more prevalent than over-reporting. The present study used levels of skin conductance and heart rate as markers for physiological reactions to social exclusion. Although skin conductance and heart rate reactivity is associated with changes in brain regions regulating the HPA axis, a more direct assessment of HPA axis responses (e.g., cortisol measures) in patients with SAD would be desirable. In addition, our study was limited by the use of the Cyberball paradigm to induce social exclusion. As mentioned above, previous studies reported that the Cyberball paradigm was not sufficient to evoke physiological responses $(45,46)$. Other paradigms that involve direct communication, negative evaluation, and rejection may be more powerful. One example would be the Trier social stress test (TSST; 91), which has been shown to cause increases in heart rate and cortisol as well as subjective reports of psycho-social stress (92). Unlike prior studies on the long-term effects of social exclusion in socially anxious subjects, the present study used a waiting period of 15 minutes instead of a 45-min-delay. Testing potential additional effects of peer victimization and social anxiety after a longer delay would be a desirable extension of the present study. Finally, generalizability of our findings is restricted by the high rate of female subjects. Although social anxiety disorder is more prevalent among women (93-95), prevalence rates were found to be equal for both sexes in clinical samples. A more appropriate sex ratio would be worthwhile in further investigations.

\section{CONCLUSION}

Experiences of social exclusion cause immediate affective and physiological reactions. Although the effects of being rejected are not linked to psychopathology or previous social experiences in general, the extent, and continuity of affective and physiological responses is determined by prior experiences of peer victimization rather than social anxiety. In addition, the present study is consistent with previous reports indicating the existence and significance of associative networks and associative memory processing (19, 20), reflecting processes that may be considered as social traumatization. However, non-associative memory mechanisms (96) and epigenetic mechanisms $(97,98)$ might also contribute to the effects of emotional traumatization.

\section{REFERENCES}

1. Boney-McCoy S, Finkelhor D. Psychosocial sequelae of violent victimization in a national youth sample. J Consult Clin Psychol (1995) 63(5):726-36. doi:10.1037/0022-006X.63.5.726

2. Danielson CK, de Arellano MA, Kilpatrick DG, Saunders BE, Resnick HS. Child maltreatment in depressed adolescents: differences in symptomatology based on history of abuse. Child Maltreat (2005) 10(1):37-48. doi:10.1177/ 1077559504271630

3. Kendall-Tackett KA, Williams LM, Finkelhor D. Impact of sexual abuse on children: a review and synthesis of recent empirical studies. Psychol Bull (1993) 113(1):164-80. doi:10.1037/0033-2909.113.1.164

4. Kilpatrick DG, Ruggiero KJ, Acierno R, Saunders BE, Resnick HS, Best CL. Violence and risk of PTSD, major depression, substance abuse/dependence, and comorbidity: results from the National Survey of Adolescents. J Consult Clin Psychol (2003) 71(4):692-700. doi:10.1037/0022-006X.71.4.692
5. Schneider R, Cronkite R, Timko C. Lifetime physical and sexual abuse and substance use treatment outcomes in men. J Subst Abuse Treat (2008) 35(4):353-61. doi:10.1016/j.jsat.2008.01.001

6. Butchart A, Kahane T. Preventing Child Maltreatment: A Guide to Taking Action and Generating Evidence. Geneva: World Health Organization (2006).

7. Egeland B. Taking stock: childhood emotional maltreatment and developmental psychopathology. Child Abuse Negl (2009) 33(1):22-6. doi:10.1016/j.chiabu. 2008.12.004

8. Siegel RS, La Greca AM, Harrison HM. Peer victimization and social anxiety in adolescents: prospective and reciprocal relationships. J Youth Adolesc (2009) 38(8):1096-109. doi:10.1007/s10964-009-9392-1

9. Storch EA, Masia-Warner C, Crisp H, Klein RG. Peer victimization and social anxiety in adolescence: a prospective study. Aggress Behav (2005) 31(5):437-52. doi:10.1002/ab.20093

10. La Greca AM, Harrison HM. Adolescent peer relations, friendships, and romantic relationships: do they predict social anxiety and depression? J Clin Child Adolesc Psychol (2005) 34(1):49-61. doi:10.1207/s15374424jccp3401_5

11. Storch EA, Brassard MR, Masia-Warner CL. The relationship of peer victimization to social anxiety and loneliness in adolescence. Child Study J (2003) 33(1):1-18.

12. Storch EA, Masia-Warner C. The relationship of peer victimization to social anxiety and loneliness in adolescent females. J Adolesc (2004) 27(3):351-62. doi:10.1016/j.adolescence.2004.03.003

13. Ranta K, Kaltiala-Heino R, Pelkonen M, Marttunen M. Associations between peer victimization, self-reported depression and social phobia among adolescents: the role of comorbidity. J Adolesc (2009) 32(1):77-93. doi:10.1016/j. adolescence.2007.11.005

14. Clark DM, Wells A. A cognitive model of social phobia. In: Heimberg RG, Liebowitz MR, Hope DA, Schneier FR, editors. Social Phobia: Diagnosis, Assessment, and Treatment. New York, NY: The Guilford Press (1995). p. 69-93.

15. Heimberg RG, Brozovich FA, Rapee RM, Hofmann S, DiBartolo P. A cognitivebehavioral model of social anxiety disorder: update and extension. Soc Anxiety (2010) 2:395-422. doi:10.1016/B978-0-12-375096-9.00015-8

16. Rapee RM, Heimberg RG. A cognitive-behavioral model of anxiety in social phobia. Behav Res Ther (1997) 35(8):741-56. doi:10.1016/S0005-7967(97)00022-3

17. Beck A. The evolution of the cognitive model of depression and its neurobiological correlates. Am J Psychiatry (2008) 165(8):969-77. doi:10.1176/appi.ajp. 2008.08050721

18. Beevers CG. Cognitive vulnerability to depression: a dual process model. Clin Psychol Rev (2005) 25(7):975-1002. doi:10.1016/j.cpr.2005.03.003

19. Foa EB, Kozak MJ. Emotional processing of fear: exposure to corrective information. Psychol Bull (1986) 99(1):20-35. doi:10.1037/0033-2909.99.1.20

20. Lang PJ. A bio-informational theory of emotional imagery. Psychophysiology (1979) 16(6):495-512. doi:10.1111/j.1469-8986.1979.tb01511.x

21. Smith ER, DeCoster J. Dual-process models in social and cognitive psychology: conceptual integration and links to underlying memory systems. Pers Soc Psychol $\operatorname{Rev}(2000)$ 4(2):108-31. doi:10.1207/S15327957PSPR0402_01

22. Charney DS. Psychobiological mechanisms of resilience and vulnerability: implications for successful adaptation to extreme stress. Am J Psychiatry (2004) 161(2):195-216. doi:10.1176/appi.ajp.161.2.195

23. Blair HT, Schafe GE, Bauer EP, Rodrigues SM, LeDoux JE. Synaptic plasticity in the lateral amygdala: a cellular hypothesis of fear conditioning. Learn Mem (2001) 8(5):229-42. doi:10.1101/lm.30901

24. Hackmann A, Clark DM, McManus F. Recurrent images and early memories in social phobia. Behav Res Ther (2000) 38(6):601-10. doi:10.1016/S00057967(99)00161-8

25. Blanchard EB, Kolb LC, Gerardi RJ, Ryan P, Pallmeyer TP. Cardiac response to relevant stimuli as an adjunctive tool for diagnosing post-traumatic stress disorder in Vietnam veterans. Behav Ther (1986) 17(5):592-606. doi:10.1016/S00057894(86)80097-1

26. Dobbs D, Wilson W. Observations on persistence of war neurosis. Dis Nerv Syst (1960) 21:40-6.

27. Kolb LC. The post-traumatic stress disorders of combat: a subgroup with a conditioned emotional response. Mil Med (1984) 149:237-43.

28. Malloy PF, Fairbank JA, Keane TM. Validation of a multimethod assessment of posttraumatic stress disorders in Vietnam veterans. J Consult Clin Psychol (1983) 51(4):488-94. doi:10.1037/0022-006X.51.4.488 
29. Pitman RK, Orr SP, Forgue DF, de Jong JB, Claiborn JM. Psychophysiologic assessment of posttraumatic stress disorder imagery in Vietnam combat veterans. Arch Gen Psychiatry (1987) 44(11):970-5. doi:10.1001/archpsyc.1987. 01800230050009

30. Van der Kolk BA, Ducey CP. The psychological processing of traumatic experience: Rorschach patterns in PTSD. J Trauma Stress (1989) 2(3):259-74. doi:10.1007/BF00976231

31. Williams KD. Social ostracism. In: Kowalski RM, editor. Aversive Interpersonal Behaviors. New York: Plenum (1997). p. 133-70.

32. Williams KD. Ostracism: The Power of Silence. New York: Guilford Press (2001).

33. Gonsalkorale K, Williams KD. The KKK won't let me play: ostracism even by a despised outgroup hurts. Eur J Soc Psychol (2007) 37(6):1176-86. doi:10.1002/ ejsp.392

34. Smith A, Williams KD. R U There? Ostracism by cell phone text messages. Group Dyn (2004) 8(4):291-301. doi:10.1037/1089-2699.8.4.291

35. Williams KD, Cheung CK, Choi W. Cyberostracism: effects of being ignored over the Internet. J Pers Soc Psychol (2000) 79(5):748-62. doi:10.1037/0022-3514.79. 5.748

36. Zadro L, Williams KD, Richardson R. How low can you go? Ostracism by a computer is sufficient to lower self-reported levels of belonging, control, self-esteem, and meaningful existence. J Exp Soc Psychol (2004) 40(4):560-7. doi:10.1016/j.jesp.2003.11.006

37. Williams KD, Jarvis B. Cyberball: a program for use in research on interpersonal ostracism and acceptance. Behav Res Methods (2006) 38(1):174-80. doi:10.3758/BF03192765

38. Borland C, Zadro L, Richardson R. Effects of Ostracism on Normals and Social Phobics Over Time. Sydney: University of New South Wales (2004). [Unpublished manuscript].

39. Zadro L, Boland C, Richardson R. How long does it last? The persistence of the effects of ostracism in the socially anxious. JExp Soc Psychol (2006) 42(5):692-7. doi:10.1016/j.jesp.2005.10.007

40. Oaten M, Williams KD, Jones A, Zadro L. The effects of ostracism on selfregulation in the socially anxious. J Soc Clin Psychol (2008) 27(5):471-504. doi:10.1521/jscp.2008.27.5.471

41. Eisenberger NI, Lieberman MD. Why rejection hurts: a common neural alarm system for physical and social pain. Trends Cogn Sci (2004) 8(7):294-300. doi:10.1016/j.tics.2004.05.010

42. Eisenberger NI, Lieberman MD, Williams KD. Does rejection hurt? An fMRI study of social exclusion. Science (2003) 302(5643):290-2. doi:10.1126/science. 1089134

43. Somerville LH, Heatherton TF, Kelley WM. Anterior cingulate cortex responds differentially to expectancy violation and social rejection. Nat Neurosci (2006) 9(8):1007-8. doi:10.1038/nn1728

44. Kelly M, McDonald S, Rushby J. All alone with sweaty palms - physiological arousal and ostracism. Int J Psychophysiol (2012) 83:309-14. doi:10.1016/j. ijpsycho.2011.11.008

45. Sijtsema JJ, Shoulberg EK, Murray-Close D. Physiological reactivity and different forms of aggression in girls: moderating roles of rejection sensitivity and peer rejection. Biol Psychol (2011) 86(3):181-92. doi:10.1016/j.biopsycho.2010. 11.007

46. Krimsky MR. (2010). Exclusive Challenges in Modeling Psycho-Social Stress: The Cyberball Experience. Doctoral Dissertation, Emory University. Available from: http://pid.emory.edu/ark:/25593/1b301

47. American Psychiatric Association, editor. Diagnostic and Statistical Manual of Mental Disorders (DSM-IV-TR). 4th ed. Washington, DC: American Psychiatric Association (2000).

48. Ackenheil M, Stotz G, Dietz-Bauer R, Vossen A. Deutsche Fassung des MiniInternational Neuropsychiatric Interview. München: Psychiatrische Universitätsklinik München (1999). [Mini International Interview - German Version 5.0.0.].

49. Lecrubier Y, Sheehan D, Weiller E, Amorim P, Bonora I, Harnett Sheehan K, et al. The Mini International Neuropsychiatric Interview (MINI). A short diagnostic structured interview: reliability and validity according to the CIDI. Eur Psychiatry (1997) 12(5):224-31. doi:10.1016/S0924-9338(97)86748-X

50. Sheehan DV, Lecrubier Y, Sheehan KH, Amorim P, Janavs J, Weiller E, et al. The MINI-International Neuropsychiatric Interview (MINI): the development and validation of a structured diagnostic psychiatric interview for DSM-IV and ICD-10. J Clin Psychiatry (1998) 59:22-33.
51. Heinrichs N, Hahlweg K, Fiegenbaum W, Frank M, Schroeder B, von Witzleben I. Validitat und reliabilitat der social interaction anxiety scale (SIAS) und der social phobia scale (SPS) [Validity and reliability of the social interaction anxiety scale (SIAS) and the social phobia scale (SPS)]. Verhaltenstherapie (2002) 12(1):26-35. doi:10.1159/000056690

52. Stangier U, Heidenreich T, Berardi A, Golbs U, Hoyer J. Die Erfassung sozialer Phobie durch die Social Interaction Anxiety Scale (SIAS) und die Social Phobia Scale (SPS) [Assessment of social phobia using the Social Interaction Anxiety Scale and the Social Phobia Scale]. Z Klin Psychol (1999) 28(1):28-36. doi:10.1026//0084-5345.28.1.28

53. Sansen L, Iffland B, Catani C, Neuner F. Entwicklung und Evaluation des Fragebogens zu belastenden Sozialerfahrungen in der Peergroup (FBS) [Development and evaluation of a questionnaire on stressful social experiences in peer groups (FBS)]. Z Klin Psychol Psychother (2013) 42(1):34-44. doi:10.1026/1616-3443/ a000184

54. Wingenfeld K, Spitzer C, Mensebach C, Grabe HJ, Hill A, Gast U, et al. Die deutsche Version des Childhood Trauma Questionnaire (CTQ): erste befunde $\mathrm{zu}$ den psychometrischen Kennwerten [The German version of the Childhood Trauma Questionnaire (CTQ): preliminary psychometric properties] Psychother Psychosom Med Psychol (2010) 60(11):442-50. doi:10.1055/s-00301247564

55. Klinitzke G, Romppel M, Haeuser W, Braehler E, Glaesmer H. Die deutsche Version des Childhood Trauma Questionnaire (CTQ) - psychometrische Eigenschaften in einer bevölkerungsrepräsentativen Stichprobe [The German Version of the Childhood Trauma Questionnaire (CTQ): psychometric characteristics in a representative sample of the general population]. Psychother Psychosom Med Psychol (2012) 62(2):47-51. doi:10.1055/s-0031-1295495

56. Hautzinger M, Keller F, Kuehner C. Das Beck Depressionsinventar II. Deutsche Bearbeitung und Handbuch zum BDI II. Frankfurt am Main: Harcourt Test Services (2006).

57. Kuehner C, Buerger C, Keller F, Hautzinger M. Reliabilität und Validität des revidierten beck-depressionsinventars (BDI-II) [Reliability and validity of the revised beck depression inventory (BDI-II)]. Nervenarzt (2007) 78(6):651-6. doi:10.1007/s00115-006-2098-7

58. Derogatis LR. Brief Symptom Inventory (BSI) (Administration, Scoring, and Procedures Manual). 3rd ed. Minneapolis: National Computer Services (1993).

59. Derogatis LR, Melisaratos N. The brief symptom inventory: an introductory report. Psychol Med (1983) 13(3):595-605. doi:10.1017/S0033291700048017

60. Franke GH. BSI, Brief Symptom Inventory - Deutsche Version. Göttingen: Beltz (2000).

61. Krohne HW, Egloff B, Kohlmann CW, Tausch A. Untersuchungen mit einer Deutschen version der positive and negative affect schedule (PANAS) [Investigations with a German version of the positive and negative affect schedule (PANAS)]. Diagnostica (1996) 42:139-56.

62. Watson D, Clark LA, Tellegen A. Development and validation of brief measures of positive and negative affect: the PANAS scales. J Pers Soc Psychol (1988) 54(6):1063-70. doi:10.1037/0022-3514.54.6.1063

63. Wilhelm F, Peyk P. ANSLAB: Autonomic Nervous System Laboratory (Version 4.0). (2005). Available from: http://www. sprweb.org

64. Nagai Y, Critchley H, Featherstone E, Trimble M, Dolan R. Activity in ventromedial prefrontal cortex covaries with sympathetic skin conductance level: a physiological account of a "default mode" of brain function. Neuroimage (2004) 22(1):243-51. doi:10.1016/j.neuroimage.2004.01.019

65. Rainville P, Duncan GH, Price DD, Carrier B, Bushnell MC. Pain affect encoded in human anterior cingulate but not somatosensory cortex. Science (1997) 277(5328):968-71. doi:10.1126/science.277.5328.968

66. Lieberman MD. Social cognitive neuroscience: a review of core processes. Annu Rev Psychol (2007) 58:259-89. doi:10.1146/annurev.psych.58.110405. 085654

67. Heim C, Newport DJ, Bonsall R, Miller AH, Nemeroff CB. Altered pituitaryadrenal axis responses to provocative challenge tests in adult survivors of childhood abuse. Am J Psychiatry (2001) 158(4):575-81. doi:10.1176/appi.ajp. 158.4.575

68. Heim C, Newport DJ, Mletzko T, Miller AH, Nemeroff CB. The link between childhood trauma and depression: insights from HPA axis studies in humans. Psychoneuroendocrinology (2008) 33(6):693-710. doi:10.1016/j.psyneuen.2008. 03.008 
69. Taylor SE, Karlamangla AS, Friedman EM, Seeman TE. Early environment affects neuroendocrine regulation in adulthood. Soc Cogn Affect Neurosci (2011) 6(2):244-51. doi:10.1093/scan/nsq037

70. Carpenter LL, Carvalho JP, Tyrka AR, Wier LM, Mello AF, Mello MF, et al. Decreased adrenocorticotropic hormone and cortisol responses to stress in healthy adults reporting significant childhood maltreatment. Biol Psychiatry (2007) 62(10):1080-7. doi:10.1016/j.biopsych.2007.05.002

71. Carpenter LL, Ross NS, Tyrka AR, Anderson GM, Kelly M, Price LH. Dex/CRH test cortisol response in outpatients with major depression and matched healthy controls. Psychoneuroendocrinology (2009) 34(8):1208-13. doi:10.1016/ j.psyneuen.2009.03.009

72. Carpenter LL, Shattuck TT, Tyrka AR, Geracioti TD, Price LH. Effect of childhood physical abuse on cortisol stress response. Psychopharmacology (2011) 214(1):367-75. doi:10.1007/s00213-010-2007-4

73. Elzinga BM, Roelofs K, Tollenaar MS, Bakvis P, van Pelt J, Spinhoven P. Diminished cortisol responses to psychosocial stress associated with lifetime adverse events: a study among healthy young subjects. Psychoneuroendocrinology (2008) 33:227-37. doi:10.1016/j.psyneuen.2007.11.004

74. Klaassens ER, van Noorden MS, Giltay EJ, van Pelt J, van Veen T, Zitman FG. Effects of childhood trauma on HPA-axis reactivity in women free of lifetime psychopathology. Prog Neuropsychopharmacol Biol Psychiatry (2009) 33(5):889-94. doi:10.1016/j.pnpbp.2009.04.011

75. Kraft AJ, Luecken LJ. Childhood parental divorce and cortisol in young adulthood: evidence for mediation by family income. Psychoneuroendocrinology (2009) 34(9):1363-9. doi:10.1016/j.psyneuen.2009.04.008

76. MacMillan HL, Georgiades K, Duku EK, Shea A, Steiner M, Niec A, et al. Cortisol response to stress in female youths exposed to childhood maltreatment: results of the youth mood project. Biol Psychiatry (2009) 66(1):62-8. doi:10.1016/j.biopsych.2008.12.014

77. Tyrka AR, Wier L, Price LH, Ross N, Anderson GM, Wilkinson CW, et al. Childhood parental loss and adult hypothalamic-pituitary-adrenal function. Biol Psychiatry (2008) 63(12):1147-54. doi:10.1016/j.biopsych.2008.01.011

78. Ouellet-Morin I, Danese A, Bowes L, Shakoor S, Ambler A, Pariante CM, et al. A discordant monozygotic twin design shows blunted cortisol reactivity among bullied children. J Am Acad Child Adolesc Psychiatry (2011) 50(6):574-82. doi:10.1016/j.jaac.2011.02.015

79. Ouellet-Morin I, Odgers CL, Danese A, Bowes L, Shakoor S, Papadopoulos AS, et al. Blunted cortisol responses to stress signal social and behavioral problems among maltreated/bullied 12-year-old children. Biol Psychiatry (2011) 70(11):1016-23. doi:10.1016/j.biopsych.2011.06.017

80. Lovallo WR, Farag NH, Sorocco KH, Cohoon AJ, Vincent AS. Lifetime adversity leads to blunted stress axis reactivity: studies from the Oklahoma Family Health Patterns Project. Biol Psychiatry (2012) 71:344-9. doi:10.1016/j.biopsych.2011. 10.018

81. Blechert J, Michael T, Grossman P, Lajtman M, Wilhelm FH. Autonomic and respiratory characteristics of posttraumatic stress disorder and panic disorder. Psychosom Med (2007) 69(9):935-43. doi:10.1097/PSY.0b013e31815a8f6b

82. Cuthbert BN, Lang PJ, Strauss C, Drobes D, Patrick CJ, Bradley MM. The psychophysiology of anxiety disorder: fear memory imagery. Psychophysiology (2003) 40(3):407-22. doi:10.1111/1469-8986.00043

83. McTeague LM, Lang PJ, Laplante MC, Cuthbert BN, Shumen JR, Bradley MM. Aversive imagery in posttraumatic stress disorder: trauma recurrence, comorbidity, and physiological reactivity. Biol Psychiatry (2010) 67:346-56. doi:10.1016/j.biopsych.2009.08.023

84. Lupien SJ, McEwen BS, Gunnar MR, Heim C. Effects of stress throughout the lifespan on the brain, behaviour and cognition. Nat Rev Neurosci (2009) 10(6):434-45. doi:10.1038/nrn2639

85. Schulkin J. Allostasis: a neural behavioral perspective. Horm Behav (2003) 43:21-7. doi:10.1016/S0018-506X(02)00035-1

86. Cornwell BR, Johnson L, Berardi L, Grillon C. Anticipation of public speaking in virtual reality reveals a relationship between trait social anxiety and startle reactivity. Biol Psychiatry (2006) 59(7):664-6. doi:10.1016/j.biopsych.2005.09.015
87. Lissek S, Levenson J, Biggs AL, Johnson LL, Ameli R, Pine DS, et al. Elevated fear conditioning to socially relevant unconditioned stimuli in social anxiety disorder. Am J Psychiatry (2008) 165(1):124-32. doi:10.1176/appi.ajp.2007. 06091513

88. McTeague LM, Lang PJ, Laplante MC, Cuthbert BN, Strauss CC, Bradley MM. Fearful imagery in social phobia: generalization, comorbidity, and physiological reactivity. Biol Psychiatry (2009) 65(5):374-82. doi:10.1016/j.biopsych. 2008.09.023

89. Haeuser W, Schmutzer G, Braehler E, Glaesmer H. Maltreatment in childhood and adolescence: results from a survey of a representative sample of the German population. Dtsch Arztebl Int (2011) 108(17):287-94. doi:10.3238/arztebl.2011. 0287

90. Hardt J, Rutter M. Validity of adult retrospective reports of adverse childhood experiences: review of the evidence. J Child Psychol Psychiatry (2004) 45(2):260-73. doi:10.1111/j.1469-7610.2004.00218.x

91. Kirschbaum C, Pirke KM, Hellhammer DH. The 'Trier Social Stress Test' - a tool for investigating psychobiological stress responses in a laboratory setting. Neuropsychobiology (1993) 28(1-2):76-81. doi:10.1159/000119004

92. Kudielka BM, Schommer NC, Hellhammer DH, Kirschbaum C. Acute HPA axis responses, heart rate, and mood changes to psychosocial stress (TSST) in humans at different times of day. Psychoneuroendocrinology (2004) 29(8):983-92. doi:10. 1016/j.psyneuen.2003.08.009

93. Kessler RC, Chiu WT, Demler O, Walters EE. Prevalence, severity, and comorbidity of 12-month DSM-IV disorders in the National Comorbidity Survey Replication. Arch Gen Psychiatry (2005) 62(6):617-709. doi:10.1001/archpsyc. 62.6.617

94. Ruscio AM, Brown TA, Chiu WT, Sareen J, Stein MB, Kessler RC. Social fears and social phobia in the USA: results from the National Comorbidity Survey Replication. Psychol Med (2008) 38(01):15-28. doi:10.1017/S0033291707001699

95. Wittchen HU, Fehm L. Epidemiology and natural course of social fears and social phobia. Acta Psychiatr Scand (2003) 108(417):4-18. doi:10.1034/j.16000447.108.s417.1.x

96. Kamprath K, Wotjak CT. Nonassociative learning processes determine expression and extinction of conditioned fear in mice. Learn Mem (2004) 11:770-86. doi: $10.1101 / \mathrm{lm} .86104$

97. McGowan PO. Epigenomic mechanisms of early adversity and HPA dysfunction: considerations for PTSD research. Front Psychiatry (2013) 4:110. doi:10.3389/fpsyt.2013.00110

98. Maddox SA, Watts CS, Doyère V, Schafe GE. A naturally-occuring histone acetyltransferase inhibitor derived from garcinia indica impairs newly acquired and reactivated fear memories. PLoS One (2013) 8(1):e54463. doi:10.1371/journal. pone. 0054463

Conflict of Interest Statement: The authors declare that the research was conducted in the absence of any commercial or financial relationships that could be construed as a potential conflict of interest.

Received: 06 December 2013; paper pending published: 10 January 2014; accepted: 03 March 2014; published online: 18 March 2014.

Citation: Iffland B, Sansen LM, Catani C and Neuner F (2014) The trauma of peer abuse: effects of relational peer victimization and social anxiety disorder on physiological and affective reactions to social exclusion. Front. Psychiatry 5:26. doi: $10.3389 /$ fpsyt.2014.00026

This article was submitted to Child and Neurodevelopmental Psychiatry, a section of the journal Frontiers in Psychiatry.

Copyright (c) 2014 Iffland, Sansen, Catani and Neuner. This is an open-access article distributed under the terms of the Creative Commons Attribution License (CC BY). The use, distribution or reproduction in other forums is permitted, provided the original author(s) or licensor are credited and that the original publication in this journal is cited, in accordance with accepted academic practice. No use, distribution or reproduction is permitted which does not comply with these terms. 